\title{
IMPACT OF KNOWLEDGE SHARING DETERMINANTS ON IMPROVING PERFORMANCE OF FACILITIES MANAGEMENT
}

\author{
Irwan Mohammad $\mathrm{Ali}^{1 *}$, Mohd Azian Zaidi ${ }^{1}$, Kharizam Ismail ${ }^{2}$, \\ Mohamed Imran Mohamed Ariff ${ }^{3}$
}

${ }^{1}$ Department of Building Surveying, Faculty of Architecture, Planning and Surveying, Universiti Teknologi MARA, Perak Branch, Seri Iskandar Campus, Seri Iskandar, 32610 Perak, Malaysia ${ }^{2}$ Department of Quantity Surveying, Faculty of Architecture, Planning and Surveying, Universiti Teknologi MARA, Perak Branch, Seri Iskandar Campus, Seri Iskandar, 32610 Perak, Malaysia ${ }^{3}$ Department of Computer Science, Faculty of Computer and Mathematical Sciences, Universiti Teknologi MARA, Perak Branch, Tapah Campus, Tapah Road, 35400 Perak, Malaysia

(Received: July 2018 / Revised: September 2018 / Accepted: December 2018)

\begin{abstract}
The delivery process for facilities management (FM) is critical during operational and maintenance stages when it ensures that all facilities are at their best performance in support of organization business operation. Since this stage takes place in a very complex and uncertain environment, an effective approach must be used to ensure successful FM. Most organization know of the importance of knowledge sharing (KS) to organizational performance; thus, the main purpose of this research is to examine the impact of KS determinants on improving performance of FM. The primary method used in this research was a deductive approach that strategically used a questionnaire survey technique to collect data. A set of questionnaires was developed and distributed to targeted respondents who were directly involved in FM operations. The response rate from these surveys was high at $74 \%$. Data were analyzed using structural equation modelling and SmartPLS 3.0 software. Results showed that working culture, staff attitude, motivation to share and opportunities to share had significant impacts on improving performance of FM operations, while the nature of knowledge to share did not significantly impact FM operational performance. Thus, this research proposed a KS model for improving FM operations.
\end{abstract}

Keywords: Determinants; Facilities management; Improving performance; Knowledge sharing; Operational performance

\section{INTRODUCTION}

After the completion of building construction, the operational and maintenance phases commence, which are facilities management (FM) or service delivery. FM is important to support successful business operations and to meeting business goals (Pathirage et al., 2008). Typical FM activities are categorized into four groups: facility planning, real estate and building construction, building operations and maintenance, and general office services (Barrett $\&$ Finch, 2013). In the case of private finance initiative (PFI) projects, FM operational performance is even more critical than conventional procurement in term of measuring concession performance and payment mechanism based on service delivered.

\footnotetext{
${ }^{*}$ Corresponding author's email: irwan9471@perak.uitm.edu.my, Tel. +60-05-3742000, Fax. +60-05-3742018 Permalink/DOI: https://doi.org/10.14716/ijtech.v9i8.2761
} 
The operational and maintenance phases of PFI projects are subject to high risk for operational failure and impact on development because of technical and practical demands over the lifecycle of a PFI contract, as well as challenging maintenance services activities (Nutt, 2000; Chotipanich, 2004; Alexander, 2013; Mustapa, 2013). Isa et al., (2017) demonstrated that FM has a significant function in value management that improves quality of projects, products, and service value. Thus, FM service providers must accept challenges to defining and providing maintenance services to ensure their facilities' adequate performance. PFI projects during the FM service delivery stage can be monitored based on service delivery output and payment mechanisms. Thus, this stage is critical to maintaining or improving organizational performance during the concession or contract period. In particular, Nurcahyo et al. (2015) highlighted that the performance of every business activity or operation can be measured using key performance indicators (KPI), which are used to determine an organization's success in achieving its strategic objectives.

Most organization acknowledge the importance of knowledge sharing (KS) to organizational performance, and research has been conducted to show that KS significantly contributes to improving organizational performance (Hartono \& Sheng, 2016). Bartol and Srivastava (2002) viewed $\mathrm{KS}$ as the sharing of organizationally relevant information, ideas, suggestions, and expertise through the exchange of experiences and thoughts that allow individuals to gain greater understanding of a phenomenon. Thus, $\mathrm{KS}$ is the communication of all types of knowledge, including explicit and tacit knowledge (Hansen, 2002).

Accordingly, KS has become an important tool for maintaining a competitive advantage among organizations. Numerous studies have demonstrated that KS provides other advantages as well, such as enhancing organizational performance and development (Ismail \& Yusof, 2009; Mohd Zin, 2013). Thus, KS should have a positive impact on improving the performance of FM operations, and the main purpose of the current research is to examine the impact of KS determinants on improving the performance of FM.

\section{RESEARCH CONCEPTUAL MODEL}

First, a conceptual model was developed based on the theory of planned behavior (TPB). This theory is the most influential social psychological model for explaining and forecasting human behavior in specific contexts (Ajzen, 2001). The TPB is defined as an individual's intention to perform a given behavior and is generally assumed to capture the motivational factors that determine individual behaviors, such as effort and willingness to perform a behavior.

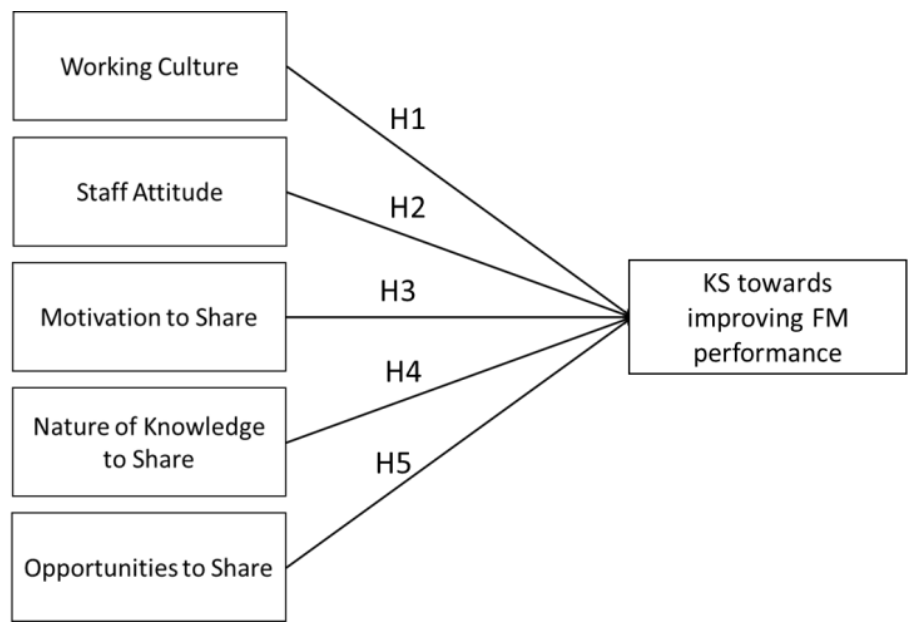

Figure 1 Research conceptual model 
The conceptual model was developed based on five KS determinants; working culture (WC), staff attitude (SA), motivation to share (MV), nature of knowledge to Share (NK) and opportunities to share (OP). This research conceptual model consists of 22 items for independent variables and five dependent variables. Consequently, five hypotheses were established based on the research conceptual model, as shown in Figure 1.

Hypothesis 1 - There is a significant relationship between WC and KS that improves the performance of FM consisting of fairness, creativity, diversity, corporate vision and social ties.

Hypothesis 2 - There is a significant relationship between SA and KS that improves the performance of FM consisting of openness, enjoy helping others, mentoring and responsibility.

Hypothesis 3 - There is a significant relationship between MV and KS that improves the performance of FM consisting of rewards, recognition sense of belonging, training and development

Hypothesis 4 - There is a significant relationship between NK and KS that improves the performance of FM consisting of value of knowledge, tacit knowledge, explicit knowledge, and access to knowledge

Hypothesis 5 - There is a significant relationship between OP and KS that improves the performance of FM consisting of knowledge as power, technology, time, infrastructure, and knowledge self-efficacy.

\section{METHODS}

The main purpose of this research was to examine the impact of KS determinants on improving the performance of FM. The primary methods used were a deductive approach that strategically employed a questionnaire survey technique to collect data, while analysis was conducted using the structural equation modelling (SEM) approach and partial least squares structural equation modeling (PLS-SEM) software. The analysis was carried out in two stages: the measurement model analysis and the structural model analysis. The measurement model analysis involved examining the adequacy of model by analyzing the relationships between each determinant factor and items in independent and dependent variables. The results of the analysis are explained below.

\subsection{Sample Size}

The population identified for this research consists of key players in FM at 16 PFI campuses. As identified in the previous section, the sampling unit of analysis for this research was FM practitioners, represented by FM staff in these 16 organizations. Therefore, the minimum sample size for this research is was between 109 for a $95 \%$ confidence level with a $5 \%$ confidence interval (error margin); and 171 for a $99 \%$ confidence level with a $5 \%$ confidence interval (see Table 1).

Table 1 Sample size

\begin{tabular}{lllllll}
\hline \multirow{2}{*}{ Population size } & \multicolumn{2}{l}{ Confidence level (95\%) } & \multicolumn{4}{l}{ Confidence level (99\%) } \\
\cline { 2 - 7 } & \multicolumn{2}{l}{ Margin of error } & \multicolumn{4}{l}{ Margin of error } \\
\hline \multirow{2}{*}{151} & $5 \%$ & $2.5 \%$ & $1 \%$ & $5 \%$ & $2.5 \%$ & $1 \%$ \\
\hline
\end{tabular}




\subsection{Respondent's Profile}

Respondents who were directly involved in FM PFI projects were identified and invited to take part in the survey. Frequency descriptive analysis was carried out to obtain background information about the respondents who answered the questionnaires, consisting of several categories including gender, age, academic qualification, position in the FM organization, and experiences of the respondents in FM PFI projects.

A total of 151 questionnaires were distributed via a web-based, self-administrative questionnaire, and 114 responses were recorded. Only 111 responses were considered valid for analysis and three responses were rejected for negative responses on reverse questions. Therefore, the response rate for this survey was $74 \%$, which is high response rate for a small population.

Table 2 Respondent profile

\begin{tabular}{llcrc}
\hline Category & Indicator & Frequency & $\begin{array}{c}\text { Valid } \\
\text { percent }\end{array}$ & $\begin{array}{c}\text { Cumulative } \\
\text { percent }\end{array}$ \\
\hline \multirow{4}{*}{ Qualification } & Certificate & & 26.1 & 26.1 \\
& Biploma & 29 & 33.3 & 59.4 \\
& Total & 37 & 40.5 & \\
& Facility manager & 45 & 100.0 & 100.0 \\
\hline \multirow{5}{*}{ Position } & 111 & 13.5 & 13.5 \\
& Building surveyor & 15 & 9.9 & 23.4 \\
& Quantity surveyor & 11 & 7.2 & 30.6 \\
& Engineer (civil, electrical, mechanical) & 8 & 27.0 & 57.6 \\
& Architect/landscape architect & 30 & 2.7 & 60.3 \\
& Assistant engineer (civil, electrical, mechanical) & 3 & 39.6 & \\
& Total & 111 & 100.0 & 100.0 \\
\hline \multirow{5}{*}{ FM } & Less than 2 years & 14 & 12.6 & 12.6 \\
experience & 3-5 years & 29 & 26.1 & 38.7 \\
& 6-8 years & 27 & 24.3 & 63.1 \\
& More than 10 years & 16 & 14.4 & 77.5 \\
& Total & 25 & 22.5 & \\
\hline
\end{tabular}

A detailed overview of the demographic profiles of the respondents in this main survey is presented in Table 2. The majority of the respondents had bachelor's degrees ( 45 respondents: 40.5\%), followed by diplomas (37 respondents: 33.3\%) and certificates (29 respondents: $26.1 \%$ ) as the highest educational qualification. In terms of position in an organization, most responses were from assistant engineers (civil, electrical or mechanical; 44 respondents: $39.6 \%$ ), followed by engineers (civil, electrical or mechanical; 30 respondents: $27 \%$ ), facility managers (15 respondents: 13.5\%) and building surveyors (11 respondents: $9.9 \%)$. The lowest response rates came from quantity surveyor and architects or landscape architects with 8 respondents (7.2\%) and 3 respondents $(2.7 \%)$, respectively. This reflects the reality of organizational hierarchy in FM at higher learning institutions and PFI projects, both of which are dominated by assistant engineers.

Respondents' experience in FM was identified with the highest responses from respondents that had 3-5 years of experiences (26.1\%), followed by respondents with 6-8 years of experiences $(24.3 \%)$ and those with more than 10 years of experiences $(22.5 \%)$. The lowest response rate came from respondents with have 9-10 years of experiences and those with less than 2 years of experiences ( $14.4 \%$ and $12.6 \%$, respectively). 


\section{RESULTS AND DISCUSSION}

\subsection{SEM}

A further analysis technique used in this research was SEM which is a multivariate analysis technique based on principles used in regression analysis that overcomes substantial and statistical problems of more traditional methods. In this analysis, there are two assessments conducted: measurement model assessments and structural model assessment.

\subsubsection{Measurement model assessment}

The assessment of measurement is essential and necessary for providing thorough testing of the reliability and validity of research model. It is also employed to measure latent constructs and their manifest variables (Loehlin, 1998). In the current research, several stages were used for the assessment of the measurement model including determining convergent validity and discriminant validity for independent and dependent variables. All loadings were greater than 0.40 , with most loadings exceeding 0.60 , except loadings for the average variance extracted (AVE). Factor loadings ranged from 0.501 to 0.963 . Items with loadings less than 0.70 were considered significant (Hair Jr et al., 2010). High factor loadings indicate that measurements had convergent validity. All construct factor loadings exceeded the 0.50 cut-off, with the exception of AVE.

Normally, the acceptable AVE threshold is 0.5 (Hair Jr et al., 2010). However, for this research, the AVE was less than 0.5 and considered insufficient. According to Ping (2009), even if an AVE is lower than 0.5, a new model can still be tested, and not all scholars accept AVE as crucial to establishing convergent validity. Low AVE at an initial stage of model testing should be viewed as exploratory and accepted until perfect observation is attained. In some research context, AVE less than 0.5 is also can be acceptable (Fornell \& Larcker, 1981). Every KS determinant was found to have adequate convergent validity based on good composite reliability (>0.60); thus, based on results in Table 3, the study's measurement model demonstrated an adequate convergent validity.

Table 3 Convergent validity

\begin{tabular}{lccc}
\hline \multicolumn{1}{c}{ KS determinant } & AVE & $\begin{array}{c}\text { Composite } \\
\text { reliability }\end{array}$ & $\begin{array}{c}\text { Cronbach's } \\
\text { Alpha }\end{array}$ \\
\hline Working culture & 0.296471 & 0.654777 & 0.886339 \\
Staff attitude & 0.294805 & 0.625691 & 0.858933 \\
Motivation to share & 0.541381 & 0.746521 & 0.818055 \\
Nature of knowledge to share & 0.349878 & 0.556700 & 0.796649 \\
Opportunity to share & 0.315885 & 0.623885 & 0.851403 \\
Knowledge sharing & 0.392566 & 0.763010 & 0.924021 \\
\hline
\end{tabular}

The next step in the construct validation process is the assessment of discriminant validity. Here, discriminate validity was evaluated by examining the cross loadings of each construct item and the square root of AVE calculated for each construct. All items should have higher loading on their corresponding construct than cross loadings on other constructs in the model. The square root of AVE for all factors should be greater than all the correlations between that construct and other constructs. Table 4 shows that the diagonal values of AVE (in bold in Table 4) are greater than the off-diagonal AVE. Hence, the test established discriminant validity.

\subsubsection{Structural Model Assessment}

The next step in the process is to assess the path coefficient of all KS determinants (paths) by comparing beta $(\beta)$ values among all paths. The path coefficient represents hypothesized relationships between KS determinants on improving FM performances. 
Table 4 Discriminate validity

\begin{tabular}{lccccccc}
\hline & AVE & WC & SA & MV & NK & OP & KS \\
\hline Working culture & 0.296471 & $\mathbf{0 . 5 4 4} *$ & & & & & \\
Staff attitude & 0.294805 & & $\mathbf{0 . 5 4 3}$ & & & & \\
Motivation to share & 0.541381 & & & $\mathbf{0 . 7 1 3}^{*}$ & & & \\
Nature of knowledge to share & 0.349878 & & & & $\mathbf{0 . 5 8 8}^{*}$ & & \\
Opportunities to share & 0.315885 & & & & & $\mathbf{0 . 5 6 0} *$ & \\
Knowledge sharing & 0.392566 & & & & & & $\mathbf{0 . 6 2 6}^{*}$ \\
\hline
\end{tabular}

Note: The values of diagonal AVE are greater than the off-diagonal AVE, where diagonal values present the AVE values

The highest $\beta$ value indicates the strongest impact of KS determinants (independent variables) on improving the performance of FM (dependent variables). According to Hair Jr et al., (2014), path coefficients should exceed 0.10 to account for a certain impact within a model. However, the $\beta$ value must be tested for its significance level through the t-value test, carried out by performing a nonparametric bootstrapping technique (Chin, 1998).

Therefore, a bootstrap resampling method was employed to test the statistical significance of each path coefficient. The number of resample iterations was 5,000 to generate a stable estimation, as suggested by Henseler et al. (2016). According to Hair Jr et al. (2014), it is suggested that acceptable t-values for a two-tailed test are 1.64 (significance level $=0.10$ or $10 \%), 1.96($ significance level $=0.05$ or $5 \%)$ and 2.58 (significance level $=0.01$ or $1 \%)$.

Table 5 Results of hypothesis tests

\begin{tabular}{|c|c|c|c|c|}
\hline Hypothesis & Relationship & $\begin{array}{c}\text { Path } \\
\text { coefficient } \\
/ \beta\end{array}$ & t-value & Remarks \\
\hline$H 1$ & $\begin{array}{l}\text { Working culture > } \\
\text { KS improves performance of FM }\end{array}$ & 0.050 & $2.597 * * *$ & Significant \\
\hline$H 2$ & $\begin{array}{l}\text { Staff attitude > } \\
\text { KS improves performance of FM }\end{array}$ & 0.173 & $8.829 * * *$ & Significant \\
\hline$H 3$ & $\begin{array}{l}\text { Motivation to share } \\
\text { KS improves performance of FM }\end{array}$ & 0.433 & $30.944 * * *$ & Significant \\
\hline$H 4$ & $\begin{array}{l}\text { Nature of knowledge to share }> \\
\text { KS improves performance of FM }\end{array}$ & -0.059 & $8.829 * * *$ & Not significant \\
\hline$H 5$ & $\begin{array}{l}\text { Opportunities to share > } \\
\text { KS improves performance of FM }\end{array}$ & 0.348 & $27.984 * * *$ & Significant \\
\hline
\end{tabular}

Results from Table 5 show that the $\beta$ values attained are higher than the cut-off point value of 0.01 for WC, SA, MV and OP, as suggested by Hair Jr et al. (2014). The highest $\beta$ value for KS determinants which indicates the most significant impacts on $\mathrm{KS}$, was for MV $(\beta=0.433)$, followed by OP $(\beta=0.348)$. The t-values were higher than minimum cut-off significance values, which were at least 0.01 or $1 \%$. This indicates that $\mathrm{WC}, \mathrm{SA}, \mathrm{MV}$ and OP factors have significant impacts on FM performance in this study. Only one KS determinant which is the $\mathrm{NK}$, had irrelevant impacts on KS and associated improvements on the performance of FM operations.

\subsection{Hypothesis Results}

\subsubsection{Working culture}

Results from the analysis show that the path coefficient of the KS determinant WC for improving the performance of FM operations was significant $(\beta=0.050$; $t$-value $=2.597 * * *$, 
$\mathrm{p}<0.01)$. Thus, this hypothesis is accepted. Since WC in FM is quite challenging to develop, it is suggested to encourage fairness among employees so that they can focus on organizational goals. WC also ensures that corporate visions can be attained and allows organizational members to network successfully in the long term.

\subsubsection{Staff attitude}

The path coefficient for the KS determinant SA for improving the performance of FM operations also had a significant impact $(\beta=0.173$; $\mathrm{t}$-value $=8.829 * * *, \mathrm{p}<0.01)$. Thus, this hypothesis is accepted. In an FM organization, employees can have either positive or negative attitudes toward specific tasks or jobs. When employees are pleased and are actively involved in ensuring successful organizational performance, SAs are more likely to be positive. In uncertain working environments, openness is vital to create confidence among FM organizational members. If employees have good relationships, they will improve their personal achievements and performance. Most employees' personal achievements often include enjoy helping others (Krogh et al., 2000). At the same time, mentoring by experienced staff is key to developing less-experienced FM staff and their personal growth. Ensuring that every employee thinks that the performance of FM operations is their main responsibility should be a priority.

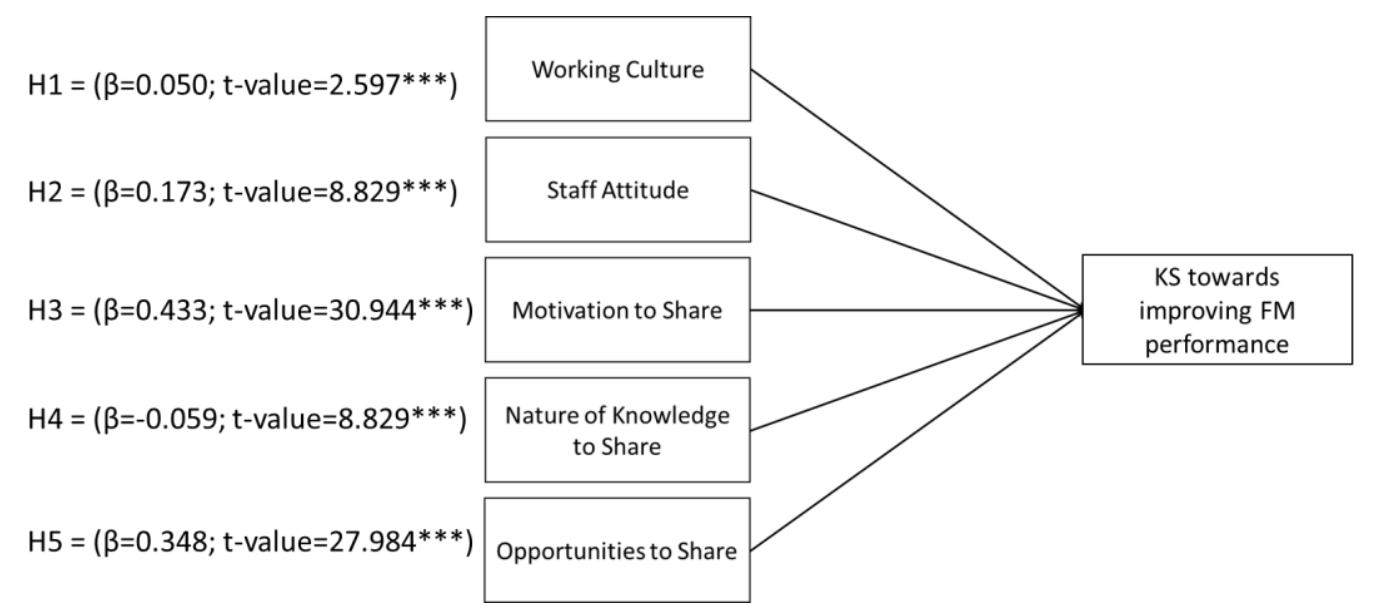

Figure 2 Hypothesis results for each KS determinant

\subsubsection{Motivation to share}

The path coefficient for the KS determinant MV for improving the performance of FM operations had a significant impact $(\beta=0.433$; $\mathrm{t}$-value $=30.944 * * *, \mathrm{p}<0.01)$. Thus, this hypothesis is accepted. Frequently, rewards are a common motivational factor to share knowledge in FM organizations. Therefore, employees know that hard work and meeting goals will be rewarded (e.g. financial rewards or promotions). Another motivational factor that can increase $\mathrm{KS}$ is recognizing employees as experts who are skilled in FM operations. Additionally, a sense of belonging encourages organizational members to willingly contribute to sharing knowledge and encourage them to contribute positively to organizational performance which in turn affects their work behaviors, job performance, and career success.

\subsubsection{Nature of knowledge to share}

Results from the analysis show that the path coefficient for the KS determinant NK for improving the performance of FM operations had a significant impact $(\beta=-0.059$; $\mathrm{t}$-value $=$ $8.829 * * *, \mathrm{p}<0.01$ ). Thus, this hypothesis is not accepted. This KS determinant should still be considered in various research context because numerous studies indicate that NK has a significant relationship with KS, which improves organizational performance (Ipe, 2003). 


\subsubsection{Opportunities to share}

Results from the analysis show that the path coefficient for the KS determinant OP for improving the performance of FM operations had a significant impact $(\beta=0.348$; $\mathrm{t}$-value $=$ $27.984 * * *, \mathrm{p}<0.01)$. Thus, this hypothesis is accepted. The complexity of FM operational tasks requires time to find solutions; therefore, allocation of a time to share knowledge is essential to enhancing KS among employees and, in turn, FM performance. An FM organization must also be supported with good infrastructure that can support the KS process, although most successful modern organizations are supported by advanced IT platforms such as online applications and supporting devices.

\section{CONCLUSION}

In this study, the significant impact of KS determinants on improving FM operational performance was identified. Four hypotheses (i.e., WC, SA, MV, and OP) had a significant impact on improving FM performance, but the hypothesis for NK was not accepted and had no significant impact on improving FM performance. Therefore, FM organizations could implement KS more strategically to improve operational performance. Since this study was exploratory, it is suggested that a longitudinal research approach should be used for future research focused on the definite effects of $\mathrm{KS}$ after incentive or encouragement to improve organizational performance management based on the hypotheses is implemented.

\section{ACKNOWLEDGEMENT}

This research was part of ongoing PhD research at the Faculty of Architecture, Planning and Surveying, Universiti Teknologi MARA, Cawangan Perak and funded under Geran Insentif Khas Penyeliaan Perak. The authors would like to express their deepest gratitude to the Faculty of Architecture, Planning and Surveying and the Universiti Teknologi MARA, Cawangan Perak.

\section{REFERENCES}

Ajzen, I., 2001. Nature and Operation of Attitudes. Annual Review of Psychology, Volume 52(1), pp. 27-58

Alexander, K., 2013. Facilities Management: Theory and Practice. Taylor \& Francis, New York, USA

Barrett, P., Finch, E., 2013. Facilities Management: The Dynamics of Excellence. Wiley. United Kingdom

Bartol, K.M., Srivastava, A., 2002. Encouraging Knowledge Sharing: The Role of Organizational Reward Systems. Journal of Leadership \& Organizational Studies, Volume 9(1), pp. 64-76

Chin, W.W., 1998. Commentary: Issues and Opinion on Structural Equation Modeling. MIS Quarterly. MIS Quarterly, Volume 22(1), pp. VII-XVI

Chotipanich, S., 2004. Positioning Facility Management. Facilities, Volume 22(13/14), pp. 364-372

Fornell, C., Larcker, D.F., 1981. Evaluating Structural Equation Models with Unobservable Variables and Measurement Error. Journal of Marketing Research, Volume 18(1), pp. 3950

Hair Jr, J.F., Sarstedt, M., Hopkins, L., Kuppelwieser, V., 2014. Partial Least Squares Structural Equation Modeling (PLS-SEM). European Business Review, Volume 26(2), pp. 106-121

Hair Jr, J.F., Black, W.C., Babin, B.J., Anderson, R.E., 2010. Multivariate Data Analysis. Pearson. London

Hansen, M.T., 2002. Knowledge Networks: Explaining Effective Knowledge Sharing in 
Multiunit Companies. Organization Science, Volume 13(3), pp. 232-248

Hartono, R., Sheng, M.L., 2016. Knowledge Sharing and Firm Performance: The Role of Social Networking Site and Innovation Capability. Technology Analysis \& Strategic Management, Volume 28(3), pp. 335-347

Henseler, J., Hubona, G., Ray, P.A., 2016. Using PLS Path Modeling in New Technology Research: Updated Guidelines. Industrial Management \& Data Systems, Volume 116(1), pp. $2-20$

Ipe, M., 2003. Knowledge Sharing in Organizations: A Conceptual Framework. Human Resource Development Review, Volume 2(4), pp. 337-359

Isa, N.M., Kamaruzzaman, S.N., Mohamed, O., Berawi, M.A., 2017. Review of Facilities Management Functions in Value Management Practices. International Journal of Technology, Volume 8(5), pp. 830-840

Ismail, M.B., Mohammad Yusof, Z., 2009. Demographic Factors and Knowledge Sharing Quality among Malaysian Government Officers. In Communications of the IBIMA (Volume 9). Available Online at https://ibimapublishing.com/articles/CIBIMA/2009/385564/385564.pdf, Accessed on October 16, 2018

Krogh, G.V., Ichijo, K., Nonaka, I., 2000. Enabling Knowledge Creation: How to Unlock the Mystery of Tacit Knowledge and Release the Power of Innovation. Oxford University Press. New York, USA

Loehlin, J.C., 1998. Latent Variable Models: An Introduction to Factor, Path, and Structural Analysis. Lawrence Erlbaum Associates Publishers. New Jersey, USA

Mohd Zin, I.N., 2013. Knowledge Sharing Approaches in Malaysian Construction Organisations for Improved Performance. Ph.D Thesis, University of Salford, united Kingdom

Mustapa, M., 2013. Facilities Management Knowledge in Private Finance Initiative (PFI) Healthcare Projects. PhD Thesis, Loughborough University, United Kingdom

Nurcahyo, R., Wibowo, A.D., Putra, R.F.E., 2015. Key Performance Indicators Development for Government Agency. International Journal of Technology, Volume 6(5), pp. 856-863

Nutt, B., 2000. Four Competing Futures for Facility Management. Facilities, Volume 18(3/4), pp. $124-132$

Pathirage, C., Haigh, R., Amaratunga, D., Baldry, D., 2008. Knowledge Management Practices in Facilities Organisations: A Case Study. Journal of Facilities Management, Volume 6(1), pp. 5-22

Ping, R.A., 2009. Is There Any Way to Improve Average Variance Extracted (AVE) in a Latent Variable (LV) $\mathrm{X}$ (Revised)?. Availale Online at http://www.wright.edu/ robert.ping/ImprovAVE2.doc, Accessed on October 16, 2018 